\title{
INVERS MOORE PENROSE SEBAGAI INVERS MATRIKS
}

\author{
Yuli Yanti, Helmi, Mariatul Kiftiah
}

\begin{abstract}
INTISARI
Pada umumnya invers matriks hanya dapat dicari untuk matriks persegi dan nonsingular dengan bentuk invers dari suatu matriks $A$ yaitu $A^{-1}$. Untuk matriks singular dan nonsingular invers matriks berupa invers Moore Penrose yang dapat dicari dengan $A^{+}=G^{*}\left(G G^{*}\right)^{-1}\left(F^{*} F\right)^{-1} F^{*}$, dengan $A^{+}$ merupakan invers Moore Penrose dari matriks A, matriks $G$ dan $F$ merupakan matriks yang diperoleh dari baris tak nol dan kolom yang memuat satu utama dari matriks $A$, setelah dilakukan operasi baris elementer. Penelitian ini bertujuan untuk mengkaji formula invers Moore Penrose dan menerapkan formula yang didapat pada pencarian invers matriks untuk solusi sistem persamaan linear. Hasil yang dipenuhi menyatakan bahwa invers Moore Penrose dari suatu matriks A akan didapat ketika $\operatorname{rank}(A)>0$.
\end{abstract}

kata kunci: matriks, invers, invers Moore Penrose.

\section{PENDAHULUAN}

Matriks adalah jajaran empat persegi panjang dari bilangan, bilangan-bilangan dalam jajaran tersebut disebut entri dari matriks [1]. Matriks dapat digunakan untuk menyelesaikan suatu permasalahan dalam matematika seperti mencari solusi dari sistem persamaan linear yaitu dengan memanfaatkan invers matriks. Penggunaan invers matriks sangat penting dalam menentukan solusi dari sistem persamaan linear $A x=b$ yang sesuai, yakni $x=A^{-1} b$ [2]. Tetapi, pada umumnya invers matriks yang biasa dikenal hanya dapat dicari ketika matriks tersebut persegi dan nonsingular. Dengan demikian, diperlukan suatu generalisasi invers dari suatu matriks $A$ yang memenuhi $A A^{-} A=A$, dengan $A^{-}$sebagai generalisasi invers dari matriks $A$, sehingga untuk matriks yang bukan persegi juga memiliki generalisasi invers apabila memenuhi persamaan tersebut.

Pada tahun 1954, Rooger Penrose dalam penelitiannya memperkenalkan suatu jenis invers matriks yaitu invers Moore Penrose. Invers Moore Penrose merupakan invers dari matriks $A$ yang memenuhi keempat persamaan Penrose dan dilambangkan dengan $A^{+}$. Jika invers matriks biasa dikenal adalah invers dari suatu matriks persegi dan nonsingular, maka invers Moore Penrose ada untuk setiap matriks baik matriks persegi singular maupun matriks yang bukan persegi [3]. Berdasarkan hal tersebut maka penelitian ini mengkaji tentang formula invers Moore Penrose dari suatu matriks $A$.

\section{GENERALISASI INVERS}

Invers matriks pada umumnya dapat dicari apabila matriks tersebut persegi dan nonsingular. Akan tetapi, untuk matriks yang nonpersegi dan singular dapat ditentukan invers matriksnya dan tidak tunggal, yang disebut sebagai generalisasi invers. Suatu matriks disebut sebagai generalisasi invers yaitu ketika suatu matriks memenuhi persamaan pada Definisi 1 berikut ini. Generalisasi invers dapat dicari dengan menggunakan aturan algoritma, yang diberikan pada Contoh 2.

Definisi 1 [7] Diberikan matriks $A \in \mathbb{R}_{m \times n}$. Matriks $A^{-}$disebut sebagai generalisasi invers dari $A \in \mathbb{C}_{m \times n}$ apabila memenuhi $A A^{-} A=A$.

Berikut ini diberikan contoh dari generalisasi invers. 
Contoh 2. Diberikan matriks $A$ berukuran $2 \times 3$ dengan $A=\left[\begin{array}{lll}2 & 1 & 7 \\ 3 & 4 & 2\end{array}\right]$, tentukan generalisasi invers dari matriks $A$.

Penyelesaian: dengan menggunakan aturan algoritma diperoleh bahwa generalisasi invers dari matriks $A$ sebagai berikut,

a. Diperoleh matriks hasil operasi baris elementer yaitu $\left[\begin{array}{ccc}1 & 0 & 12 \\ 0 & 1 & -14\end{array}\right]$, sehingga $\operatorname{rank}(A)=2$.

b. Pilih sebarang matriks $2 \times 2$ dari $A$ misalkan $B=\left[\begin{array}{ll}2 & 1 \\ 3 & 4\end{array}\right]$

c. Mencari invers dari $B$ yaitu $B^{-1}$ dan $\left(B^{-1}\right)^{t}$.

$$
\begin{gathered}
B^{-1}=\left[\begin{array}{cc}
0,8 & -0,2 \\
-0,6 & 0,4
\end{array}\right] \\
\left(B^{-1}\right)^{t}=\left[\begin{array}{cc}
0,8 & -0,6 \\
-0,2 & 0,4
\end{array}\right]
\end{gathered}
$$

d. Pada matriks $A$ ganti elemen $B$ dengan $\left(B^{-1}\right)^{t}$ dan ganti elemen lainnya dengan nol

$B=\left[\begin{array}{ccc}0,8 & -0,6 & 0 \\ -0,2 & 0,4 & 0\end{array}\right]$

e. Transposekan matriks $B$ diperoleh $A^{-}=\left[\begin{array}{cc}0,8 & -0,2 \\ -0,6 & 0,4 \\ 0 & 0\end{array}\right]$.

Selanjutnya, ditunjukkan $A^{-}$memenuhi $A A^{-} A=A$

$$
A A^{-} A=\left[\begin{array}{lll}
2 & 1 & 7 \\
3 & 4 & 2
\end{array}\right] A^{-}=\left[\begin{array}{cc}
0,8 & -0,2 \\
-0,6 & 0,4 \\
0 & 0
\end{array}\right]\left[\begin{array}{lll}
2 & 1 & 7 \\
3 & 4 & 2
\end{array}\right]=\left[\begin{array}{lll}
2 & 1 & 7 \\
3 & 4 & 2
\end{array}\right]=A
$$

Jadi, terbukti bahwa $A^{-}$merupakan generalisasi invers dari $A$.

\section{INVERS MOORE PENROSE}

Invers Moore Penrose merupakan invers dari suatu matriks yang memenuhi keempat persamaan Penrose. Invers Moore Penrose dapat digunakan untuk mencari invers matriks yang singular dan nonsingular, dan matriks yang diperoleh tunggal, berdasarkan pada pada Teorema 4 . Berikut ini diberikan definisi tentang empat persamaan yang harus dipenuhi dari suatu matriks, sehingga matriks tersebut disebut matriks invers Moore Penrose.

Definisi 3 [4]. Diberikan matriks $A \in \mathbb{R}_{m \times n}$. Matriks $A^{+}$merupakan invers Moore Penrose dari matriks A jika memenuhi:
1. $A A^{+} A=A$
2. $A^{+} A A^{+}=A^{+}$
3. $\left(A A^{+}\right)^{*}=A A^{+}$
4. $\left(A^{+} A\right)^{*}=A^{+} A$

dengan * merupakan konjugat transpose dari suatu matriks.

Berikut ini diberikan teorema ketunggalan dari invers Moore Penrose sebagai berikut,

Teorema 4 [5] Diberikan matriks $A \in \mathbb{R}_{m \times n}$, jika invers matriks $A$ memenuhi keempat persamaan Penrose maka invers Moore Penrose adalah tunggal.

Bukti: Misalkan terdapat matriks $A \in \mathbb{R}_{m \times n}$ dengan $X, Y$ adalah invers Moore Penrose dari $A$. Ditunjukkan bahwa invers dari matriks $A$ adalah tunggal, sehingga matriks $X=Y$.

$$
\begin{aligned}
X & =X A X & & \text { Berdasarkan definisi } 3 \text { bagian } 1 \\
& =X(A X)^{*} & & \text { Berdasarkan definisi } 3 \text { bagian } 2 \\
& =X(A Y A X)^{*} & & \text { Berdasarkan definisi } 3 \text { bagian } 1 \\
& =X(A X A Y) & & \text { Berdasarkan sifat konjugat transpose }
\end{aligned}
$$




$$
\begin{aligned}
& =X A Y \\
& =(X A Y A)^{*} Y \\
& =Y A X A Y \\
& =Y A Y \\
& =Y
\end{aligned}
$$

Berdasarkan definisi 3 bagian 1

Berdasarkan definisi 3 bagian 1

Berdasarkan sifat konjugat transpose

Berdasarkan definisi 3 bagian 1

Jadi, terbukti bahwa invers Moore Penrose adalah tunggal.

Berdasarkan definisi 3 bagian 2

Berikut ini diberikan teorema yang menyatakan bahwa invers matriks persegi nosingular sama dengan invers Moore Penrose.

Teorema 5 [5] Jika $A \in \mathbb{R}_{m \times m}$ merupakan matriks nonsingular maka invers dari A merupakan invers Moore Penrose, dengan kata lain invers matriks A sama dengan invers Moore Penrose.

\section{Bukti:}

Diketahui matriks $A$ merupakan matriks nonsingular, sehingga matriks $A$ memiliki invers misalkan dengan matriks $B$. Ditunjukkan bahwa untuk setiap matriks $A \in \mathbb{R}_{m \times m}$ memiliki invers yang sama dengan invers Moore Penrose. Dengan demikian, ditunjukkan bahwa matriks $B=A^{-1}$ memenuhi untuk keempat persamaan Penrose, yang ditunjukkkan sebagai berikut,

i. $\quad A B A=A A^{-1} A=I_{m} A=A$

ii. $B A B=A^{-1} A A^{-1}=A^{-1} I_{m}=A^{-1}$

iii. $(A B)^{*}=\left(A A^{-1}\right)^{*}=\left(I_{m}\right)^{*}=I_{m}=A A^{-1}$

iv. $(B A)^{*}=\left(A^{-1} A\right)^{*}=\left(I_{m}\right)^{*}=I_{m}=A^{-1} A$

Karena matriks $B$ memenuhi keempat persamaan Penrose, maka terbukti bahwa invers matriks persegi nonsingular sama dengan invers Moore Penrose atau $A^{-1}=A^{+}$.

Berikut diberikan contoh dari suatu matriks persegi yang memiliki invers matriks sama dengan invers Moore Penrose, karena memenuhi keempat dari persamaan Penrose berdasarkan pada Teorema 5.

Contoh 6. Misalkan matriks $A$ berukuran $2 \times 2$, dengan $A=\left[\begin{array}{ll}1 & 3 \\ 2 & 7\end{array}\right]$. Tunjukkan bahwa $A^{-1}=A^{+}$ Penyelesaian: Diketahui $A=\left[\begin{array}{ll}1 & 3 \\ 2 & 7\end{array}\right]$ dan diperoleh bahwa $A^{-1}=\left[\begin{array}{cc}7 & -3 \\ -2 & 1\end{array}\right]$. Selanjutnya ditunjukkan bahwa $A^{-1}$ memenuhi keempat persamaan Penrose sebagai berikut.

i. $A A^{-1} A=\left[\begin{array}{ll}1 & 3 \\ 2 & 7\end{array}\right]\left[\begin{array}{cc}7 & -3 \\ -2 & 1\end{array}\right]\left[\begin{array}{ll}1 & 3 \\ 2 & 7\end{array}\right]=\left[\begin{array}{ll}1 & 3 \\ 2 & 7\end{array}\right]=A$

ii. $A^{-1} A A^{-1}=\left[\begin{array}{cc}7 & -3 \\ -2 & 1\end{array}\right]\left[\begin{array}{ll}1 & 3 \\ 2 & 7\end{array}\right]\left[\begin{array}{cc}7 & -3 \\ -2 & 1\end{array}\right]=\left[\begin{array}{cc}7 & -3 \\ -2 & 1\end{array}\right]=A^{-1}$

iii. $\left(A A^{-1}\right)^{*}=A A^{-1}$

$$
\begin{gathered}
\left(\left[\begin{array}{ll}
1 & 3 \\
2 & 7
\end{array}\right]\left[\begin{array}{cc}
7 & -3 \\
-2 & 1
\end{array}\right]\right)^{*}=\left[\begin{array}{ll}
1 & 3 \\
2 & 7
\end{array}\right]\left[\begin{array}{cc}
7 & -3 \\
-2 & 1
\end{array}\right] \\
{\left[\begin{array}{ll}
1 & 0 \\
0 & 1
\end{array}\right]=\left[\begin{array}{ll}
1 & 0 \\
0 & 1
\end{array}\right]}
\end{gathered}
$$

iv. $\left(A^{-1} A\right)^{*}=A^{-1} A$

$$
\begin{gathered}
\left(\left[\begin{array}{cc}
7 & -3 \\
-2 & 1
\end{array}\right]\left[\begin{array}{ll}
1 & 3 \\
2 & 7
\end{array}\right]\right)^{*}=\left[\begin{array}{cc}
7 & -3 \\
-2 & 1
\end{array}\right]\left[\begin{array}{ll}
1 & 3 \\
2 & 7
\end{array}\right] \\
{\left[\begin{array}{ll}
1 & 0 \\
0 & 1
\end{array}\right]=\left[\begin{array}{ll}
1 & 0 \\
0 & 1
\end{array}\right]}
\end{gathered}
$$

Karena $A^{-1}$ memenuhi keempat persamaan Penrose maka terbukti bahwa $A^{-1}=A^{+}$. 
Teorema 7 [6] Diberikan matriks $A \in \mathbb{R}_{m \times n}$ maka matriks $A$ dapat dinyatakan sebagai $A\left(A^{*} A\right)^{-1} A^{*} A=A$.

Bukti:

Misalkan terdapat suatu matriks $A \in \mathbb{R}_{m \times n}$, berikut ini ditunjukkan bahwa $A\left(A^{*} A\right)^{-1} A^{*} A=A$, sehingga diperoleh,

$$
\begin{aligned}
A\left(A^{*} A\right)^{-1} A^{*} A & =A\left(\left(A^{*} A\right)^{-1}\left(A^{*} A\right)\right) \\
& =A I \\
& =A
\end{aligned}
$$

Jadi, terbukti bahwa $A\left(A^{*} A\right)^{-1} A^{*} A=A$.

Berikut ini diberikan teorema terbentuknya formula dari invers Moore Penrose.

Teorema 8 [6] Diberikan matriks $A \in \mathbb{R}_{m \times n}$ maka matriks $A^{+}$dapat dinyatakan dengan $A^{+}=$ $A^{*} A\left(A^{*} A A^{*} A\right)^{-1} A^{*}$.

Bukti:

Diketahui matriks $A$ dengan persamaan $A x=b$. Berdasarkan Teorema 5 bahwa $A^{-1}=A^{+}$. Sehingga untuk solusi dari sistem persamaan linear $A x=b$ maka $x=A^{-1} b=A^{+} b$. Pada Teorema 7 dinyatakan bahwa $A\left(A^{*} A\right)^{-1} A^{*} A=A$, selanjutnya ditunjukkan bahwa $A^{+}=A^{*} A\left(A^{*} A A^{*} A\right)^{-1} A^{*}$ sebagai berikut,

$$
\begin{aligned}
A^{*} A x & =A^{*} b \\
A^{*} A A^{+} b & =A^{*} b \\
A^{+} & =\left(A^{*} A\right)^{-1} A^{*} \\
& =\left(A^{*} A\left(A^{*} A\right)^{-1}\left(A^{*} A\right)\right)^{-1} A^{*} \\
& =\left(A^{*} A\left(A^{*} A\right)\left(A^{*} A\right)^{-1}\right)^{-1} A^{*} \\
& =A^{*} A\left(A^{*} A\right)^{-1}\left(A^{*} A\right)^{-1} A^{*} \\
& =A^{*} A\left(A^{*} A A^{*} A\right)^{-1} A^{*}
\end{aligned}
$$

Jadi, terbukti bahwa $A^{+}=A^{*} A\left(A^{*} A A^{*} A\right)^{-1} A^{*}$.

Pada Teorema 8 diperoleh bahwa $A^{+}=A^{*} A\left(A^{*} A A^{*} A\right)^{-1} A^{*}$, berikut ini diberikan akibat dari Teorema 8 yaitu sebagai berikut.

Akibat 9 [6] Jika matriks $A^{+}=A^{*} A\left(A^{*} A A^{*} A\right)^{-1} A^{*}$ maka matriks $A^{+}$dinyatakan sebagai $A^{+}=$ $A^{*}\left(A A^{*}\right)^{-1} A\left(A^{*} A\right)^{-1} A^{*}$.

Bukti:

Berdasarkan Teorema 7 diperoleh bahwa $A^{+}=A^{*} A\left(A^{*} A A^{*} A\right)^{-1} A^{*}$. Berikut ini ditunjukkan bahwa $A^{+}=A^{*}\left(A A^{*}\right)^{-1} A\left(A^{*} A\right)^{-1} A^{*}$.

$$
\begin{aligned}
A^{+} & =A^{*} A\left(A^{*} A A^{*} A\right)^{-1} A^{*} \\
& =A^{*} A\left(A^{*} A\right)^{-1}\left(A^{*} A\right)^{-1} A^{*} \\
& =A^{*} A\left(A A^{*}\right)^{-1}\left(A A^{*}\right)\left(A^{*} A\right)^{-1}\left(A^{*} A\right)^{-1} A^{*} \\
& =A^{*}\left(A A^{*}\right)^{-1}\left(A A^{*}\right) A\left(A^{*} A\right)^{-1}\left(A^{*} A\right)^{-1} A^{*} \\
& =A^{*}\left(A A^{*}\right)^{-1} A A^{*} A\left(A^{*} A\right)^{-1}\left(A^{*} A\right)^{-1} A^{*} \\
& =A^{*}\left(A A^{*}\right)^{-1} A\left(A^{*} A\right)\left(A^{*} A\right)^{-1}\left(A^{*} A\right)^{-1} A^{*} \\
& =A^{*}\left(A A^{*}\right)^{-1} A\left(A^{*} A\right)^{-1} A^{*}
\end{aligned}
$$

Jadi, diperoleh bahwa $A^{+}=A^{*}\left(A A^{*}\right)^{-1} A\left(A^{*} A\right)^{-1} A^{*}$.

Berikut ini diberikan definisi tentang matriks $A=F G$ sebagai berikut.

Definisi 10 [4] Jika $A \in \mathbb{R}_{m \times n}$ dengan $F \in \mathbb{R}_{m \times r}$ dan $G \in \mathbb{R}_{r \times m}$ maka $A=F G$ dan $r=\operatorname{rank}(A)=$ $\operatorname{rank}(F)=\operatorname{rank}(G)$. 
Teorema 11 [5] Diberikan matriks $A \in \mathbb{R}_{m \times n}$ dengan rank $(A)>0$. Jika matriks $A=F G$ maka $A^{+}=G^{*}\left(G G^{*}\right)^{-1}\left(F^{*} F\right)^{-1} F^{*}$.

Bukti:

Misalkan terdapat matriks $F \in \mathbb{R}_{m \times r}$ dan $G \in \mathbb{R}_{r \times n}$ sehingga $A \in \mathbb{R}_{m \times n}$, dan $\operatorname{rank}(A)>0$. Berikut ini ditunjukkan jika $A=F G$ maka $A^{+}=G^{*}\left(G G^{*}\right)^{-1}\left(F^{*} F\right)^{-1} F^{*}$, yaitu dengan menunjukkan bahwa $A^{+}$memenuhi keempat persamaan Penrose sebagai berikut,

(i). $A A^{+} A=F G G^{*}\left(G G^{*}\right)^{-1}\left(F^{*} F\right)^{-1} F^{*} F G$

$$
\begin{aligned}
& =F\left(G G^{*}\right)\left(G G^{*}\right)^{-1}\left(F^{*} F\right)^{-1}\left(F^{*} F\right) G \\
& =F G \\
& =A
\end{aligned}
$$

(ii). $A^{+} A A^{+}=G^{*}\left(G G^{*}\right)^{-1}\left(F^{*} F\right)^{-1} F^{*} F G G^{*}\left(G G^{*}\right)^{-1}\left(F^{*} F\right)^{-1} F^{*}$

$$
=G^{*}\left(G G^{*}\right)^{-1}\left(F^{*} F\right)^{-1}\left(F^{*} F\right)\left(G G^{*}\right)\left(G G^{*}\right)^{-1}\left(F^{*} F\right)^{-1} F^{*}
$$$$
=G^{*}\left(G G^{*}\right)^{-1}\left(F^{*} F\right)^{-1} F^{*}
$$$$
=A^{+}
$$

(iii). $\left(A A^{+}\right)^{*}=\left((F G)\left(G^{*}\left(G G^{*}\right)^{-1}\left(F^{*} F\right)^{-1} F^{*}\right)^{*}\right.$

$$
\begin{aligned}
& =\left(G^{*}\left(G G^{*}\right)^{-1}\left(F^{*} F\right)^{-1} F^{*}\right)^{*}(F G)^{*} \\
& =\left(\left(G^{*}\left(G G^{*}\right)^{-1}\left(F^{*} F\right)^{-1} F^{*}\right)^{*}(F G)^{*}\right)^{*}
\end{aligned}
$$$$
=(F G)\left(G^{*}\left(G G^{*}\right)^{-1}\left(F^{*} F\right)^{-1} F^{*}\right)
$$$$
=A A^{+}
$$

(iv). $\left(A^{+} A\right)^{*}=\left(\left(G^{*}\left(G G^{*}\right)^{-1}\left(F^{*} F\right)^{-1} F^{*}\right)(F G)^{*}\right.$

$$
\begin{aligned}
& =(F G)^{*}\left(G^{*}\left(G G^{*}\right)^{-1}\left(F^{*} F\right)^{-1} F^{*}\right)^{*} \\
& =\left((F G)^{*}\left(G^{*}\left(G G^{*}\right)^{-1}\left(F^{*} F\right)^{-1} F^{*}\right)^{*}\right. \\
& =\left(G^{*}\left(G G^{*}\right)^{-1}\left(F^{*} F\right)^{-1} F^{*}\right)(F G) \\
& =A^{+} A
\end{aligned}
$$

Karena $A^{+}$memenuhi keempat persamaan dari (i) sampai (iv), jadi terbukti bahwa $A^{+}=G^{*}\left(G G^{*}\right)^{-1}\left(F^{*} F\right)^{-1} F^{*}$.

Berikut ini adalah langkah-langkah mencari invers Moore Penrose dari formula yang telah didapat yaitu:

i. Mereduksi matriks $A$ menjadi matriks eselon baris tereduksi dan memisalkan matriks baru tersebut dengan matriks $Y$

ii. Melihat kolom yang memuat satu utama dari matriks $Y$ dan pilih kolom tersebut dari matriks $A$, misalkan matriks baru tersebut adalah matriks $F$ dan tentukan $F^{*},\left(F^{*} F\right)^{-1}$

iii. Memilih baris yang tak nol dari matriks $Y$ dan misalkan matriks $G$, tentukan $G^{*} \operatorname{dan}\left(G G^{*}\right)^{-1}$

iv. Mencari $A^{+}=G^{*}\left(G G^{*}\right)^{-1}\left(F^{*} F\right)^{-1} F^{*}$

Berikut ini diberikan contoh untuk menentukan invers Moore Penrose dari suatu matriks berdasarkan langkah-langkah tersebut.

Contoh 12. Diberikan matriks $A=\left[\begin{array}{ccc}0 & -2 & 3 \\ 3 & 6 & -3 \\ 6 & 6 & 3\end{array}\right]$. Tentukan invers Moore Penrose matriks $A$.

Penyelesaian: Diketahui $A=\left[\begin{array}{ccc}0 & -2 & 3 \\ 3 & 6 & -3 \\ 6 & 6 & 3\end{array}\right]$, Berikut ini langkah-langkah yang dilakukan untuk memperoleh invers Moore Penrose yaitu, 
i. Matriks $Y$ yang terbentuk yaitu $Y=\left[\begin{array}{ccc}1 & 0 & 2 \\ 0 & 1 & -\frac{3}{2} \\ 0 & 0 & 0\end{array}\right]$

ii. Matriks $F$ yang terbentuk adalah sebagai berikut,

$$
F=\left[\begin{array}{cc}
0 & -2 \\
3 & 6 \\
6 & 6
\end{array}\right], \quad F^{*}=\left[\begin{array}{ccc}
0 & 3 & 6 \\
-2 & 6 & 6
\end{array}\right], \quad\left(F^{*} F\right)^{-1}=\left[\begin{array}{cc}
0.1508 & -0.1071 \\
-0.1071 & 0.0893
\end{array}\right]
$$

iii. Matriks $G$ yang diperoleh yaitu,

$$
\begin{aligned}
G & =\left[\begin{array}{ccc}
1 & 0 & 2 \\
0 & 1 & -\frac{3}{2}
\end{array}\right], \quad G^{*}=\left[\begin{array}{cc}
1 & 0 \\
0 & 1 \\
2 & -\frac{3}{2}
\end{array}\right], \quad\left(G G^{*}\right)^{-1}=\left[\begin{array}{ll}
0.4483 & 0.4138 \\
0.4138 & 0.6897
\end{array}\right] \\
\text { iv. } A^{+} & =\left[\begin{array}{ccc}
0.0222 & 0.0033 & 0.0731 \\
-0.0345 & 0.0690 & 0.0345 \\
0.0961 & -0.0969 & 0.0944
\end{array}\right] .
\end{aligned}
$$

\section{SOLUSI SISTEM PERSAMAAN LINEAR}

Berikut ini diberikan teorema penyelesaian solusi dari sistem persamaan linear, dengan invers matriks yang diperoleh berupa generalisasi invers dan invers Moore Penrose pada Teorema 13 dan Teorema 15 berikut ini.

Teorema 13 [6] Diberikan $A x=b$ dan $b \in \operatorname{sp}(A)$ maka $x=A^{-} b+\left(I_{n}-A^{-} A\right) z$.

Bukti:

Diketahui $A x=b$ dan $b \in \operatorname{sp}(A)$. Berikut ini ditunjukkan jika $A x=b$ maka $x=A^{-} b+\left(I_{n}-A^{-} A\right) z$, dengan $z=A^{-} b$. Andaikan bahwa $x \neq A^{-} b+\left(I_{n}-A^{-} A\right) z$, dengan mengalikan kedua ruas persamaan dengan $A$ diperoleh sebagai berikut:

$$
\begin{aligned}
& A x \neq A A^{-} b+\left(A-A A^{-} A\right) z \\
& A x \neq A A^{-} b+(A-A) A^{-} b \\
& A x \neq A A^{-} b+0 \\
& A x \neq A A^{-} A x \\
& A x \neq b
\end{aligned}
$$

Karena $A x \neq b$ maka kontradiksi dengan pernyataan bahwa $A x=b$. Jadi, terbukti jika $A x=b$ maka $x=A^{-} b+\left(I_{n}-A^{-} A\right) z$.

Contoh 14. Tentukan solusi sistem persamaan linear berikut

$$
\begin{aligned}
& 5 x_{1}-2 x_{2}+6 x_{3}=0 \\
& -2 x_{1}+x_{2}+3 x_{3}=1
\end{aligned}
$$

Penyelesaian: diketahui matriks, $x$, dan $b$ sebagai berikut:

$A=\left[\begin{array}{ccc}5 & -2 & 6 \\ -2 & 1 & 3\end{array}\right], x=\left[\begin{array}{l}x_{1} \\ x_{2} \\ x_{3}\end{array}\right]$ dan $b=\left[\begin{array}{l}0 \\ 1\end{array}\right]$

Selanjutnya, dengan menggunakan aturan algoritma, diperoleh bahwa generalisasi invers dari matriks $A$ yaitu $A^{-}=\left[\begin{array}{ll}1 & 2 \\ 2 & 5 \\ 0 & 0\end{array}\right]$

Berikut ini merupakan solusi dari sistem persamaan linear berdasarkan dengan generalisasi invers yang didapat, yaitu sebagai berikut,

$$
x=A^{-} b+\left(I_{m}-A^{-} A\right) z
$$




$$
\begin{aligned}
& =\left[\begin{array}{l}
2 \\
5 \\
0
\end{array}\right]+\left(\left[\begin{array}{lll}
1 & 0 & 0 \\
0 & 1 & 0 \\
0 & 0 & 1
\end{array}\right]-\left[\begin{array}{ll}
1 & 2 \\
2 & 5 \\
0 & 0
\end{array}\right]\left[\begin{array}{ccc}
5 & -2 & 6 \\
-2 & 1 & 3
\end{array}\right]\right)\left[\begin{array}{ll}
1 & 2 \\
2 & 5 \\
0 & 0
\end{array}\right]\left[\begin{array}{l}
0 \\
1
\end{array}\right] \\
& =\left[\begin{array}{l}
2 \\
5 \\
0
\end{array}\right]
\end{aligned}
$$

Jadi, solusi sistem persamaan linear yaitu $x_{1}=2, x_{2}=5$ dan $x_{3}=0$.

Pada Teorema berikut ini diberikan penyelesaian untuk solusi dari sistem persamaan linear berdasarkan pada invers Moore Penrose yang diperoleh.

Teorema 15 [4] Diberikan $A \in \mathbb{R}_{m \times n}$ dan $b \in \mathbb{R}_{m}$. $A^{+} b$ adalah solusi kuadrat terkecil untuk $A x=b$. Bukti:

Diketahui $A \in \mathbb{R}_{m \times n}$ dan $b \in \mathbb{R}_{m}$, dengan $A x=b$. Ditunjukkan bahwa $A^{+} b$ merupakan solusi dari $A x=b$. Misalkan bahwa $A^{+} b$ bukan solusi dari $A x=b$, sehingga $x \neq A^{+} b$, diperoleh hasil sebagai berikut:

$$
\begin{aligned}
x & \neq A^{+} b \\
A x & \neq A A^{+} b \\
A x & \neq A A^{+} A x \\
A x & \neq A x \\
A x & \neq b
\end{aligned}
$$

Berdasarkan pemisalan diperoleh $A x \neq b$, sedangkan pada teorema diketahui bahwa $A x=b$, sehingga kontradiksi dengan pemisalan bahwa $x \neq A^{+} b$. Jadi, terbukti bahwa $x=A^{+} b$ merupakan solusi dari $A x=b$, dengan $A^{+}$merupakan invers Moore Penrose yang diperoleh dari matriks $A$ yang terbentuk pada sistem persamaan linear.

Contoh Tentukan solusi sistem persamaan linear berikut

$$
\begin{gathered}
4 x-8 y=12 \\
3 x-6 y=9 \\
-2 x+4 y=-6
\end{gathered}
$$

Penyelesaian: Diperoleh bahwa $A^{+}=\left[\begin{array}{ccc}0.0276 & 0.0207 & -0.0138 \\ -0.0552 & -0.0414 & 0.0276\end{array}\right]$. Solusi dari sistem persamaan linear tersebut adalah sebagai berikut,

$$
\begin{aligned}
x & =A^{+} b \\
& =\left[\begin{array}{ccc}
0.0276 & 0.0207 & -0.0138 \\
-0.0552 & -0.0414 & 0.0276
\end{array}\right]\left[\begin{array}{c}
12 \\
9 \\
-6
\end{array}\right] \\
& =\left[\begin{array}{c}
0.6 \\
-1.2
\end{array}\right]
\end{aligned}
$$

Jadi, solusi sistem persamaan linear yaitu $x=0,6$ dan $y=-1,2$.

\section{PENUTUP}

Formula yang digunakan untuk invers Moore Penrose adalah $A^{+}=G^{*}\left(G G^{*}\right)^{-1}\left(F^{*} F\right)^{-1} F^{*}$, dengan matriks $G$ dan $F$ ditentukan terlebih dahulu berdasarkan matriks $Y$ yang merupakan matriks eselon baris tereduksi dari matriks $A$. Langkah-langkah yang dapat dilakukan sebagai berikut:

i. Mereduksi matriks $A$ menjadi matriks eselon baris tereduksi dan memisalkan matriks baru tersebut dengan matriks $Y$

ii. Melihat kolom yang memuat satu utama dari matriks $Y$ dan pilih kolom tersebut dari matriks $A$, misalkan matriks baru tersebut adalah matriks $F$ dan tentukan $F^{*},\left(F^{*} F\right)^{-1}$ 
iii. Memilih baris yang tak nol dari matriks $Y$ dan misalkan matriks $G$, tentukan $G^{*}$ dan $\left(G G^{*}\right)^{-1}$ iv. Mencari $A^{+}=G^{*}\left(G G^{*}\right)^{-1}\left(F^{*} F\right)^{-1} F^{*}$.

Untuk solusi dari sistem persamaan linear dengan invers matriks yang diperoleh berbentuk invers Moore Penrose, maka solusi yang dicari dapat dihitung dengan $x=A^{+} b$.

\section{DAFTAR PUSTAKA}

[1]. Anton H, Rorres C. Aljabar Linear Elementer versi aplikasi edisi kedelapan jilid 1.Jakarta: Erlangga; 2004.

[2]. Anton, H. Aljabar Linier Elementer, edisi kelima.Jakarta: Erlangga; 1987

[3]. Britz, T. The Moore-Penrose Inverse Of A Free Matrix. Electronic Journal of Linear Algebra ISSN 1081-3810, Vol 16, pp. 208-215; 2007.

[4]. Campbell SL, Meyer CD. Generalized Inverses Of Linier Transformations.New York:Siam; 2009.

[5]. Ben-Israel A, Greville TNE. Generalized Inverses Theory and Aplications.New York: springer-verlag; 2003.

[6]. Yanai H, Takeuchi K, Takane Y. Projection Matrices, Generalized Inverse Matrices And Singular Value Decomposition.New york: Springer science business media; 2011.

[7]. Searle, SR. Matrix Algebra Useful For Statistic.United States of America; 1982.

YULI YANTI : Jurusan Matematika FMIPA Untan, Pontianak yuliyanti@student.untan.ac.id

HELMI : Jurusan Matematika FMIPA Untan, Pontianak helmi132205@yahoo.co.id

MARIATUL KIFTIAH : Jurusan Matematika FMIPA Untan, Pontianak kiftiahmariatul@math.untan.ac.id 